\title{
DC-link Voltage Control to Compensate Voltage Deviation for PV-BESSs Integrated System in Low-Voltage (LV) Networks
}

\author{
Gyu-sub Lee, Yun-su Kim , Jae-won Chang and Seung-il Moon \\ Seoul National University (SNU), Electrical Engineering Department, 08826 Gwanak-gu Seoul, Republic of Korea
}

\begin{abstract}
The exhaustion of fossil fuel and the greenhouse gas emission are one of the most significant energy and environmental issues, respectively. Photovoltaic (PV) generators and battery energy storage systems (BESSs) have been significantly increased for recent years. The BESSs are mainly used for smoothing active power fluctuation of the PV. In this paper, PV-BESSs integration of two DC/DC converters and one AC/DC converter is investigated and DC-link voltage control to compensate the AC voltage deviation is proposed for the PV-BESS system in low-voltage (LV) networks.
\end{abstract}

\section{Introduction}

The exhaustion of fossil fuel and environmental pollution have made high interest toward renewable energies. Therefore, researches on grid-connected photovoltaic (PV) systems have been significantly increased. The PV systems can be adopted in both low-voltage (LV) systems and higher voltage system. Numorous researches on the PV systems have been studied, especially on integrating PV-energy storage system (ESS) have been increased in recent years. Since the active power fluctuation of the PV system may make the system unstable, the ESSs are mainly used with the PV systems to prevent the system from instability. For instance, providing an average power reference to the PV system may help the stable operation of the PV-ESS integrated system in the perspective of smoothing active power.

Two types of the PV-ESS integrated systems shown in Figure 1 are investigated in this paper. An AC integrating system, depicted in Figure 1(a), uses two AC/DC converters on smoothing PV fluctuation. On the other hand, a DC integrating system, depicted in Figure 1(b), uses one $\mathrm{AC} / \mathrm{DC}$ converter. In the $\mathrm{DC}$ integrating system, two DC/DC converters should be installed for voltage stability of a common DC bus. Control strategies of the DC/DC converters and operation scheme of PV-ESS systems were proposed in [1-6]. High-gain DC/DC converters and control strategies for large-scale PV systems were proposed in [1]. Basic operation scheme of the PV-ESS system with DC integration was investigated in [2]. However, existing method didn't consider an abnormal condition of BESS and only used the BESS output for smoothing.

Unlike general high or medium voltage system, $\mathrm{X} / \mathrm{R}$ ratios of $\mathrm{LV}$ systems are under 0.5 . Because a resistive component is much bigger than an inductive component, voltage fluctuation is highly dependent on active power fluctuation. Therefore the high penetration of intermittent renewable energy sources (RESs) in the LV networks may cause voltage instability. Various types of voltage control methods in the LV networks were investigated and proposed in [7-10]. The voltage-active power $(V-P)$ droop control method was proposed and basic formulations of active and reactive power in the LV network were investigated in [7]. Relationships between voltage and active power proposed in above papers are used for proposed method. Characteristics of the LV systems are investigated in [8-9].

By smoothing active power fluctuation of PV using ESS, battery state-of-charge (SOC) should be undesirably deviated from the scheduled value. However the deviation may make the SOC value exceed the limit. An excess of the SOC limit causes under-voltage or overvoltage in the steady-state. other papers didn't consider how SOC limit affects to stability of systems. In this paper, the system voltage compensation method is proposed to mitigate voltage deviation. The proposed method was applied to the PV-ESS integrated system and tested by MATLAB/SimPowerSystems to prove its effectiveness.

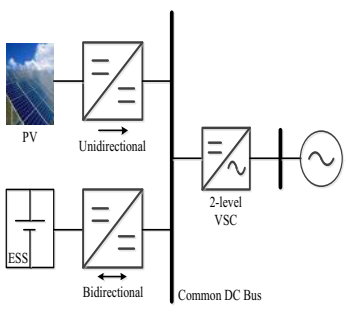

(a)

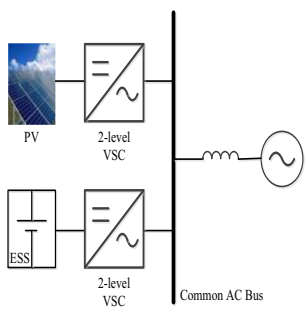

(b)
Figure 1. Two types of PV-ESS integration method 


\section{Modeling}

\subsection{Battery Energy Storage System (BESS)}

The BESSs are composed of DC voltage ans state-ofcharge (SOC). A simple battery model has proportional DC voltage to SOC. DC voltage deviation from the SOC is not considered in this paper. SOC is simply regarded as energy remaining of battery. SOC at time $t_{0}+\Delta t$ is modeled as equation (1).

$$
S O C_{t_{0}+\Delta t}=S O C_{t_{0}}-\int_{t_{0}}^{t_{0}+\Delta t} \frac{I_{d c}}{Q_{c}} d t
$$

where, $Q_{c}$ is capacity of the battery

\subsection{DC/DC Converter}

There are two types of $\mathrm{DC} / \mathrm{DC}$ converters in $\mathrm{DC}$ integrated systems. One is the DC/DC converter used in connecting the PV and a common DC bus. The other is the converter used in connecting the BESSs and the common DC bus. Current of the DC/DC converter used in the PV integrating is always positive so buck-boost converter topology is used. On the other hand, bidirectional buck-boost converter topology is used in integrating the BESSs and the common DC bus. Figure 2 is the one-way buck-boost topology and Figure 3 is the bi-directional buck-boost converter topology which are used in the PV-ESS integrated systems.

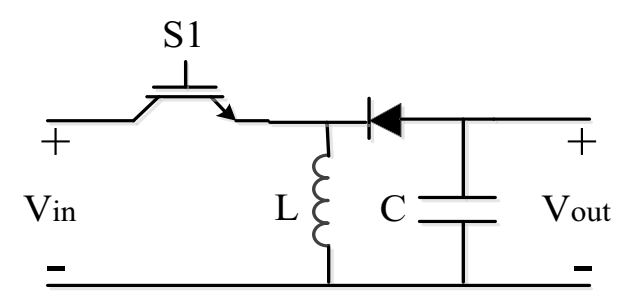

Figure 2. Simple buck-boost converter topology

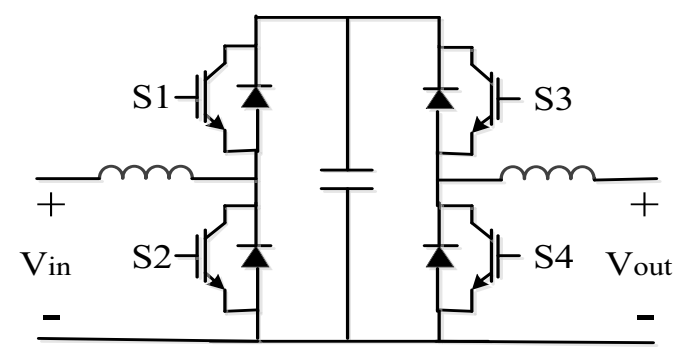

Figure 3. Bi-directional buck-boost converter topology

Both two converters have gains from 0 to inf. ideally. The DC/DC converter connected to the PV operates at maximum power point tracking (MPPT) control scheme. For using actual measurement data of the PV power, assuming the MPPT control is successfully conducted is valid. So the $\mathrm{PV}$-connected $\mathrm{DC} / \mathrm{DC}$ converter is operated by power referenced control scheme. The control scheme of the buck-boost converter is shown in Figure 4.

In the PV-BESSs integrated systems, output power of BESSs is a difference between the PV average power and the actual power. The PV average power can be calculated in many ways. The BESSs-connected DC/DC converter is also operated by power referenced control scheme and the power reference is calculated from the actual PV output power and the average output power. The control scheme of bi-directional converter is shown in Figure 5.

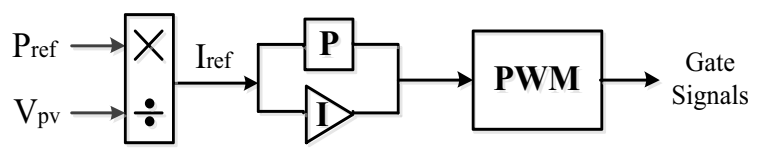

Figure 4. The control scheme of simple buck-boost converter

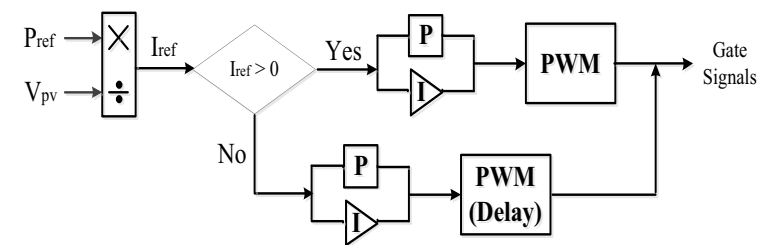

Figure 5. The control scheme of bi-directional converter

\subsection{AC/DC Converter}

Half-bridge 2-level voltage sourced converter (VSC) is used in the PV-ESS integrated systems. DC voltage of the common DC bus should be maintained constant. Therefore $V_{d c}-Q$ control scheme is used in the $\mathrm{AC} / \mathrm{DC}$ converter. The control scheme is shown in Figure 6.

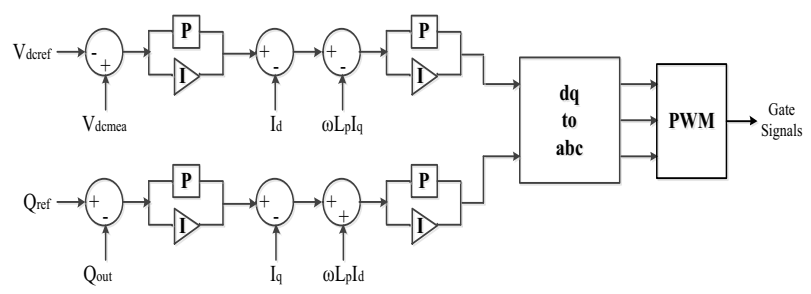

Figure 6. The control scheme of AC/DC converter

\section{DC Voltage Compensation Method}

\subsection{Formulation}

We can define a duty ratio (D) of the $\mathrm{AC} / \mathrm{DC}$ converter which means time ratio positive voltage is applied at $\mathrm{AC}$ systems. Using the duty ratio, relation between $V_{d c}$ and magnitude of equivalent AC voltage $\left(\left|V_{a c}\right|\right)$ is shown in equation (2).

$$
\left|V_{a c}\right|_{e q}=D\left(V_{d c} / 2\right)+(1-D)\left(-V_{d c} / 2\right)=(D-1 / 2) V_{d c}
$$

Equation (2) implies that steady-state AC voltage magnitude is proportional to DC voltage and the duty ratio. By using a Pulse Width Modulation (PWM), D should be changed continuously. On the other hand, DC voltage reference can be changed instantaneously. 


\subsection{SOC Limit}

General the BESSs control scheme contains ON/OFF selector based on the SOC level. If the BESSs are on charging state, the SOC is increasing proportional to DC current. Otherwise, the SOC is decreasing. At $S O C_{\min }<$ $S O C<S O C_{\max }$, the BESSs can operate in both charging and discharging state. If the $S O C=S O C_{\min }$, BESSs cannot operate in discharging state. And BESSs cannot operate in charging state at the $S O C=S O C_{\max }$.

This ON/OFF selector can make sudden output power decrease or increase because the SOC limit changes the BESSs operate mode instantaneously. This discontinuity makes output decrease or increase in steady-state. If the connected AC grid is the low-voltage (LV) system, sudden output deviation may cause voltage instability. DC-link voltage control scheme to compensate voltage deviation is proposed to relax the voltage instability

\subsection{DC-link Voltage Control for Compensation}

Sudden BESS off-signal due to SOC minimum value make voltage drop of AC bus. If the BESS control block operates on discharging state for a long time, undervoltage condition lasts for a long time. Sudden increase of DC voltage reference value can relax the under-voltage condition because $\left|V_{a c}\right|$ is proportional to $V_{d c}$. Overvoltage condition is also be relaxed by $V_{d c}$ compensation.

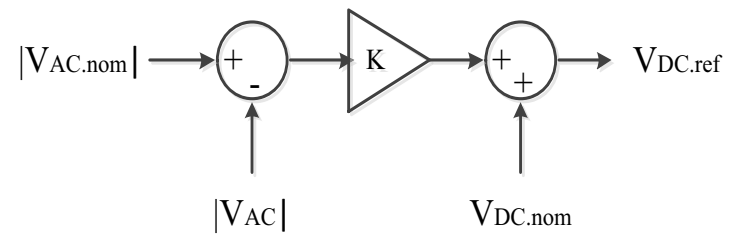

Figure 7. DC-link voltage control block

DC-link voltage control block to compensate voltage deviation is shown in Figure 7. Because compensation method can cause bad effect to smoothing the PV output, compensation gain should be adjusted to appropriate value [7]. This control scheme can be applied at lowvoltage system. In the next section, we validate proposed method using simulation

\section{Simulation}

This section presents simulation results of the PV-BESS DC integrated module and proposed method. MATLAB/SimPowerSystems simulation tools are used in validation. Table 1 is the parameters used for the proposed PV system.

Table 1. The parameter used for simulation

\begin{tabular}{|ll|}
\hline \multicolumn{2}{|c|}{ PV Module } \\
\hline DC Voltage (Vdc) & $150 \mathrm{~V}$ \\
\hline Maximum Output & $50 \mathrm{~kW}$ \\
\hline \multicolumn{2}{|c|}{ BESS Module } \\
\hline
\end{tabular}

\begin{tabular}{|l|l|}
\hline DC Voltage (Vdc) & $600 \mathrm{~V}$ \\
\hline Maximum Ouput & $50 \mathrm{~kW}$ \\
\hline Capacity (Q) & $160 \mathrm{~A} \cdot \mathrm{sec}$ \\
\hline \multicolumn{2}{|c|}{ DC/DC Converter (Bi-directional) } \\
\hline Switching Frequency & $18000 \mathrm{~Hz}$ \\
\hline Input Inductor & $10 \mathrm{mH}$ \\
\hline Output Inductor & $1 \mathrm{mH}$ \\
\hline Capacitor Other Parameter \\
\hline \multicolumn{2}{|c|}{$500 \mu \mathrm{F}$} \\
\hline DC Bus Voltage & $800 \mathrm{~V}$ \\
\hline Grid Voltage (Line-to-Line) & $560 \mathrm{~V}$ \\
\hline Grid Frequency & $60 \mathrm{~Hz}$ \\
\hline X/R Ratio & 0.15 \\
\hline
\end{tabular}

For validation of SOC minimum limit, we assume that output of BESS is always positive in the simulation. Also sum of DC current references of PV and BESS is constant. In the simulation, the value is $2.5(\mathrm{pu})$. PV data is actual measurement data of Hokkaido, Japan. We use the data with time scaling because actual fluctuation is less severe than expected one. SOC minimum limit is 0.2. Figure 8 is simulation results of under-voltage situation without DC voltage compensation. Figure 9 is simulation results of under-voltage situation with $\mathrm{DC}$ voltage compensation. Table 2 shows steady-state AC voltage

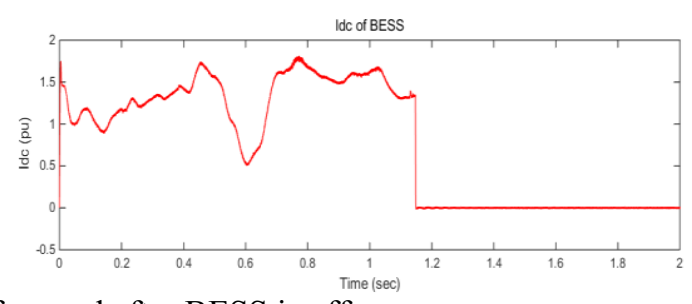

before and after BESS is off.

(a) DC current of BESS

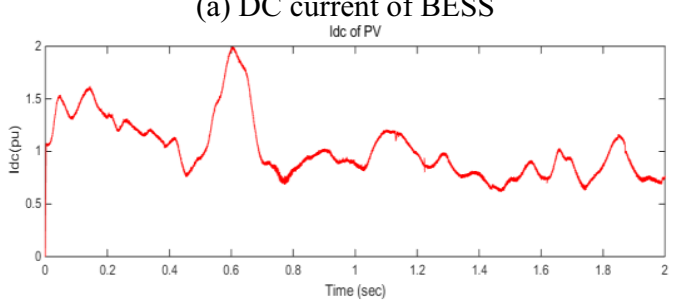

(b) DC current of PV

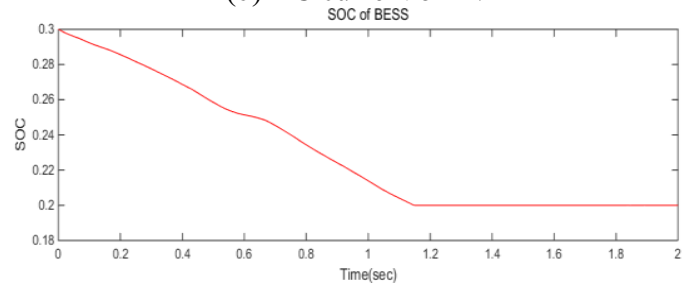

(c) SOC of BESS

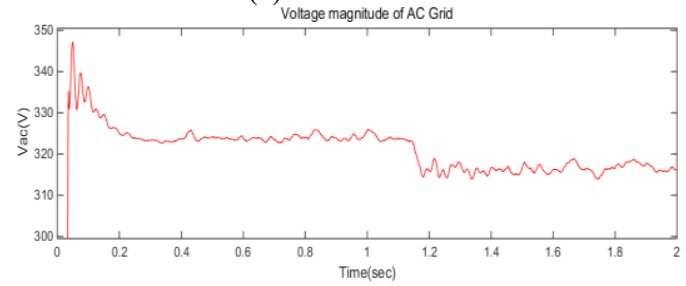

(d) Voltage magnitude of AC grid 


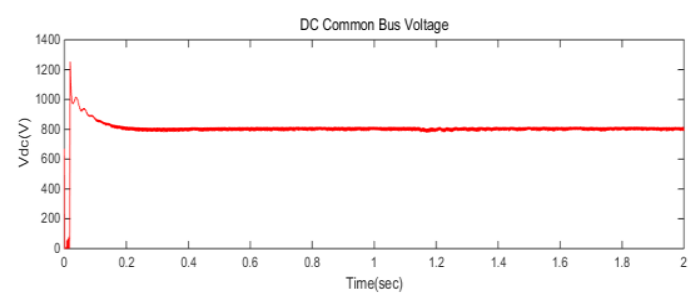

(e) DC common bus voltage

Figure 8. Simulation results without compensation scheme

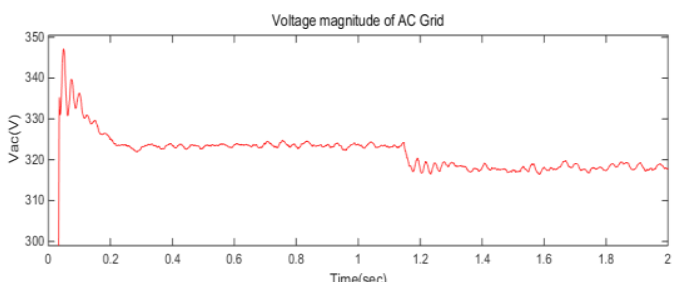

(a) Voltage magnitude of AC grid

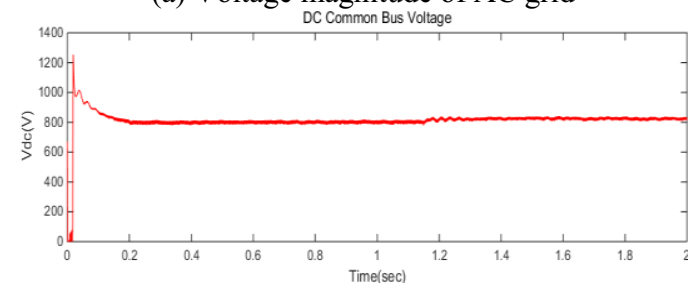

(b) DC common bus voltage

Figure 9. Simulation results with compensation scheme

Table 2. AC voltage magnitude before and after BESS is off

\begin{tabular}{|c|c|c|}
\hline & Without Compensation & With Compensation \\
\hline Before & $323 \mathrm{~V}$ & $323 \mathrm{~V}$ \\
\hline After & $315 \mathrm{~V}$ & $318 \mathrm{~V}$ \\
\hline
\end{tabular}

The SOC of BESSs reaches to its minimum value at time $1.17 \mathrm{sec}$. Because of limitation, Sudden decrease of the PV-BESSs integrated system occurs. Figure 8(d) and figure 9(a) show voltage deviation which results from the sudden power decrease. In figure $8(\mathrm{e}), \mathrm{DC}$ voltage is always constant if voltage deviation occurs. In figure 9 (b), DC voltage is increase because of the proposed compensation scheme. Voltage compensation scheme is validate in the simulation and proposed method can be novel and adequate method in voltage deviation.

\section{Conclusion}

The disadvatage of PV systems is their unstable power ouput. This unstable ouput can cause voltage instability in the LV systems. The BESSs are used for preventing the instability. However, BESSs have SOC limit in operation. If BESSs' SOC reaches its maximum or minimum value, sudden voltage deviation can occur. In this paper, DC-link voltage control to compensate the undesirable voltage deviation is proposed. Because control scheme considering SOC limit in LV networks have not been proposed, the proposed control scheme is novel. For validation of the proposed method, MATLAB/SimPowerSystems simulation tools are used. As a result of the simulation, the proposed control scheme is good for preventing voltage deviation.

\section{References}

1. D.-J. Won, Y.-S. Noh, M.-Y. Ryu, C.-Y. Won and H.-W. Lim, "A Study of Grid-connected PV-AC module with Active Power Decoupling and ESS", 2014 IEEE International Conference on Industrial Technology (ICIT), Feb. 26 Mar. 1, 2014, Busan, Korea

2. H. Choi, M. Ciobotaru and V. G. Agelidis, "LargeScale PV Systems with Energy Storage Utilizing High-Gain DC/DC Converters", 2014 IEEE International Conference on Industrial Technology (ICIT), Feb. $26 \sim$ Mar. 1, 2014, Busan, Korea

3. L. Zhang, et al. "Power control of DC microgrid using DC bus signaling" Applied Power Electronics Conference and Exposition (APEC), 2011 TwentySixth Annual IEEE. IEEE, 2011. p. 1926-1932.

4. J. J. Justo, F. Mwasilu, J. Lee and J.-W. Jang, "ACmicrogrids versus DC-microgrids with distributed energy resources: A revies", Renewable and Sustainable Energy Reviews 24, Elsevier, 2013. p. 387-405

5. M. J. E. Alam, K. M. Muttaqi and D. Sutanto, “A Novel Approach for Ramp-Rate Control of Solar PV Using Energy Storage to Mitigate Output Fluctuations Caused by Cloud Passing", IEEE Trans. on Energy Conversion vol. 29. June, 2014, p. 507518

6. F. Marra, G. Yang, C. Traeholt, J. Ostergaard and E. Larsen, "A Decentralized Storage Strategy for Residential Feeders With Photovoltaics", IEEE Trans. on Smart Grid vol. 5, March, 2014, p. 974981

7. T. L. Vandoorn, B. Meersman, L. Degroote, B. Renders and L. Vandevelde, "A Control Strategy for Islanded Microgrids With DC-Link Voltage Control", IEEE Trans. on Power Delivery vol. 26, 2011, p. 703-713

8. H. Laaksonen, P. Saari and R. Komulainen, "Voltage and Frequency Control of Inverter Based Weak LV network Microgrid", Future Power Systems 2005 International Conference on. IEEE, 2005

9. G. Mokhtari, A. Ghosh, G. Nourbakhsh and G. Ledwich, "Smart Robust Resources Control in LV Network to Deal With Voltage Rise Issue", IEEE Trans. on Sustainable Energy vol. 4, October, 2013

10. X. J. Su, M. A. S. Masoum and P. J. Wolfs, "Optimal PV Inverter Reactive Power Control and Real Power Curtailment to Improve Performance of Unbalanced Four-Wire LV Distribution Networks", IEEE Trans. on Sustainable Energy vol.5, July, 2014 